\title{
Gambaran Perilaku Disregulasi Emosi Anak Prasekolah Usia 3-4 Tahun
}

\author{
Christopora Intan Himawan Putri ${ }^{1}$, Linda Primana ${ }^{2}$ \\ ${ }^{1,2}$ Program Magister Psikologi Terapan Anak Usia Dini, Fakultas Psikologi Universitas \\ Indonesia \\ e-mail: ${ }^{1}$ christoporaintanhimawanputri@gmail.com
}

\begin{abstract}
Abstrak. Regulasi emosi merupakan kemampuan anak dalam mengekspresikan, mengenali dan mengatur emosi agar dapat ditampilkan sesuai dengan norma sosial yang berlaku. Sebaliknya, disregulasi emosi merupakan ketidakmampuan dalam meregulasi emosi. Penelitian ini bertujuan untuk mengetahui perilaku disregulasi emosi yang muncul pada anak prasekolah usia 3-4 tahun. Metode eksploratif kualitatif digunakan untuk melihat gambaran perilaku disregulasi emosi yang muncul pada anak usia 3-4 tahun. Hasil wawancara dengan guru, observasi perilaku disregulasi emosi anak serta data penunjang lainnya menunjukkan bahwa terdapat beberapa perilaku yang berhubungan dengan disregulasi emosi ada anak usia prasekolah usia 3-4 tahun. Perlu diadakan intervensi terkait perilaku disregulasi emosi anak usia prasekolah untuk mencegah perilaku agresif di masa mendatang.
\end{abstract}

Kata kunci: disregulasi emosi, regulasi emosi, prasekolah

Abstract. Emotional regulation is the ability of children to express, recognize and manage emotions to be displayed in accordance with prevailing social norms. Conversely, emotional dysregulation is an inability to regulate emotions. This study aims to determine the behavior of emotional dysregulation that appears in preschool children aged 3-4 years. Qualitative explorative method is used to see the description of emotional dysregulation behavior that appears in children aged 3-4 years. The results of interviews with teachers, observation of emotional dysregulation behavior of children and other supporting data indicate that there are some behaviors associated with emotional dysregulation there are preschool children aged 3-4 years. Interventions regarding the behavior of emotional dysregulation of preschool-aged children need to be organized to prevent aggressive behavior in the future

Keywords: disregulation emotion, regulation emotional, preschool

Anak usia prasekolah berada pada tahap kognitif praoperasional (Crain, 2011). Pada tahap ini anak menggunakan symbolic function dalam merepresentasikan seseorang yang memiliki makna melekat pada dirinya denga menggunakan kata-kata, angka maupun gambar. Salah satu cara anak menunjukkan symbolic function adalah dengan deferred imitations dimana anak mengimitasi suatu perilaku pada beberapa hal setelah mengamatinya (Papalia \& Martorell, 2012). Lebih lanjut lagi, pada masa ini anak sudah mampu memahami sebab-akibat dan semakin dapat membayangkan apa yang mungkin dirasakan oleh orang lain (Papalia \& Martorell, 2012). 
Salah satu aspek yang belum matang dari tahap praoperasional adalah centration yaitu kecenderungan untuk berpusat pada satu aspek dari situasi dan mengabaikan yang lain (Papalia \& Martorell, 2012). Salah satu bentuk centration yang menjadi ciri dari tahap praoperasional adalah egosentris. Egosentris merupakan istilah yang digunakan oleh Piaget untuk menjelaskan bahwa anak sangat terpusat pada sudut pandang mereka (Papalia \& Martorell, 2012). Egosentris yang dimiliki oleh anak usia prasekolah dan teman sebaya berpotensi memicu adanya konflik saat anak sedang berinteraksi (Armga, Blunk \& Russel, 2017). Padahal pada perkembangan sosial emosi anak, kebutuhan anak untuk berinteraksi dan membina hubungan dengan teman sebaya merupakan tugas perkembangan anak usia 3-4 tahun (Morrison, 2009). Regulasi emosi berperan sebagai kunci dari kemampuan anak dalam mengelola tuntutan dan konflik yang mereka hadapi ketika berinteraksi dengan orang lain (Dennies \& others, 2009; Lewis, Todd, \& Xu, 2011).

Regulasi emosi merupakan tindakan yang dilakukan oleh seseorang untuk mengendalikan emosi yang ingin dialaminya, bagaimana dan kapan emosi tersebut dimunculkan, bagaimana cara mengekspresikan emosi tersebut atau bagaimana ekspresi emosi tersebut terlihat oleh orang lain (Gross 1998, Westphal \& Bonanno, 2004 dalam Macklem, 2008). Pada anak regulasi emosi digambarkan sebagai, kemampuan dalam mengenali emosi diri sendiri dan orang lain serta kemampuan mengkomunikasikan perasaannya (Papalia \& Martorell, 2014). Sebagai kemampuan untuk mengendalikan emosi, regulasi emosi juga berperan untuk mengatur ekspresi emosi (positif dan negatif) dalam berinteraksi dengan orang lain sesuai dengan aturan sosial (Basilio \& Whitebread, 2012; Havighurst, 2013).

Proses perkembangan anak yang lambat dalam meregulasi perilaku mereka menjadi isu pada asepek sosialemosional anak pada masa prasekolah (Gestwicki, 2007). Denham, (2003) menyebutkan bahwa anak yang tidak mudah marah, dan terlihat bahagia, akan lebih disukai oleh teman bermainnya, dan dianggap sebagai anak yang ramah dan mudah diajak bekerja sama oleh guru (Denham, Bassett dan Wyatt, 2007). Anak yang lebih baik dalam meregulasi emosi menunjukkan agresi yang lebih rendah saat berinteraksi dengan teman sebaya, permasalahan tingkah laku yang lebih sedikit di prasekolah dan sekolah dasar (Denham et.al dalam Raikes et.al, 2006).

Sebaliknya, anak yang kurang baik dalam meregulasi emosinya, dapat memunculkan perilaku bermasalah dan dapat berlanjut ketika anak menginjak usia remaja dan dewasa, jika dibandingkan dengan anak yang memiliki kemampuan meregulasi emosi yang baik (Denham, et. al 2002; Robins, \& Rutter, 1990, dalam Havighurst S. S., Wilson, K. R., Harley, A. E., Koheo, C., Efron, D., Prior, M. R., 2013), misalnya munculnya masalah agresi atau depresi. Sejalan dengan itu, penelitian longitudinal menunjukkan bahwa ketidakmampuan untuk meregulasi emosi merupakan faktor resiko penting dalam pembentukan perilaku agresif (Roll , Koglin \& Petermann, 2012). Ketidakmampuan dalam meregulasi emosi dinamakan sebagai disregulasi emosi.

Anak yang mengalami disregulasi emosi memiliki permasalahan dalam mengatur emosi mereka dan terlibat dalam perilaku agresif ataupun hiperaktif dengan tingkat tinggi (Dickstein, Gouley, Miller, Seifer \& Shields, 2004). Perilaku-perilaku tersebut beresiko 
tinggi menjadi perilaku maladaptif di lingkungan sekolah. Contoh profil perilaku disregulasi emosi yang muncul pada anak usia prasekolah di kelas antara lain adalah berteriak, tidak dapat menunggu, tuntutan yang harus terpenuhi, menyakiti, merusak barang milik sendiri, merusak barang milik orang lain, memukul, tidak dapat duduk dengan tenang, serta berlarian terus menerus (Achenbach, Edelbrock \& Howell, 1987). Perilaku-perilaku tersebut tentu saja tidak sesuai dengan norma sosial dan berpotensi merugikan diri sendiri dan orang lain.

Penelitian ini bertujuan untuk melihat gambaran perilaku disregulasi emosi yang muncul pada anak prasekolah usia 3-4 tahun. Dengan mengetahui gambaran perilaku disregulasi emosi ini maka diharapkan orang dewasa seperti oang tua dan guru dapat menindaklanjuti hal tersebut dengan cara yang tepat. Mengingat bahwa orang dewasa seperti orang tua; guru maupun pengasuh memiliki peranan yang cukup besar di dalam perkembangan emosi dan regulasi emosi (Tanyel, 2009).

\section{METODE}

Orang tua dan guru kelas mengisi lembar infom concent. Khusus bagi orang tua yang setuju anaknya terlibat dalam penelitian ini mengisi kuesioner Family Background Questionaire yang berfungsi untuk mengetahui data demografis anak.

Sampel sebanyak 9 anak dengan rentang usia 38 bulan sampai 52 bulan yang berada pada salah satu prasekolah di Jakarta dan terlibat dalam penelitian ini. Anak-anak yang terlibat dalam penelitian ini berasal dari etnis yang beragamm, $78 \%$ adalah anak dengan jenis kelamin laki-laki dan 22\% adalah anak dengan jenis kelamin perempuan. $34 \%$ anak berasal dari etnis campuran, 22\% anak berasal dari etnis Jawa dan 11\% masing-masing untk anak dengan etnis Minangkabau, Betawi, Tionghoa dan Melayu. 100\% anak-anak berasal dari keluarga dengan tingkat ekonomi menengah ke atas. Pengelompokan status sosial-ekonomi didasarkan pada kesulitan partisipan dalam mengeluarkan uang untuk membeli dan membayar hal-hal yang penting, seperti makanan, kontrak atau sewa rumah, pembayaran rekening pendidikan anak atau perawatan kesehatan. Hal ini juga dibuktikan dengan biaya operasional triwulan anak untuksekolah sebesar $\mathrm{Rp}$ 13.000.000,00.

Awalnya peneliti melakukan diskusi dan menyamakan persepsi mengenai perilaku disregulasi emosi selanjutnya peneliti menanyakan hal mengenai perilaku disregulasi emosi anak. Setelah melakukan wawancara, peneliti melakukan observasi terhadap perilaku anak dengan menggunakan tehnik interval recording untuk mengamati kemunculan perilaku terkait disregulasi emosi yang muncul pada diri anak.

Dari hasil wawancara, guru menyampaikan bahwa terdapat beberapa anak yang sering menunjukkan tingkah laku yang berpotensi agresif serta sulit mengelola emosi muncul. Sebelumnya telah dilakukan persamaan persepsi antara peneliti dengan guru terkait perilaku disregulasi yang berkesesuaian dengan teori yang sudah dibahas sebelumnya. Perilaku disregulasi emosi umumnya muncul pada kegiatan bantu diri (memakai dan membuka sepatu, memakai tas dan makan), saat bermain bebas ataupun kegiatan lain 
sepeeri berbaris bersama atau menari. Guru mengakui perilaku-perilaku tersebut memengaruhi dinamika kelas. Strategi yang dicoba diterapkan oleh guru terkait permasalahan regulasi emosi ini adalah: 1) saat kegiatan bantu diri anak diajak untuk berdialog secara personal dengan menenangkan anak dan diberi sedikit bantuan agar anak tetap bisa mencoba sendiri, 2) jika ada konflik terkait rebutan mainan, pertama-tama guru akan menenangkan anak yang menangis kemudian mencoba mengajak berdialog anak yang melakukan tindakan agresi (seperti memukul atau mendorong), 3) selalu mengajak anak dalam kegiatan kelompok kecil atau berpasangan dengan tujuan agar anak bisa menjalin interaksi secara personal dengan teman sebaya.

\section{HASIL}

Pada analisis kebutuhan tersebut diidentifikasi bahwa lima dari sembilan anak yang berada pada satu kelas mengalami permasalah perilaku disregulasi emosi. Sebagai bentuk tindak lanjut dari analisis kebutuhan, peneliti melakukan baseline terkait perilaku disregulasi emosi. Hasil asesmen baseline dapat dilihat pada tabel berikut.

Tabel 1.

Perilaku Disegulasi Emosi Subyek

\section{Perilaku Disregulasi Emosi}

Melempar benda (mainan, tas, sepatu, tempat makan)

Berteriak ke arah teman atau guru

Berlarian di kelas

Mendorong teman

Memukul teman

Menjerit

Mencakar teman atau guru

Selanjutnya peneliti melakukan observasi dengan menggunakan behavioral checklist dengan tehnik interval recording berdasarkan data yang diperoleh dari wawancara tersebut. Data baseline merupakan penjabaran persentase perilaku subjek kelas yang muncul selama periode yang disajikan dalam bentuk grafik. Penyajian data berupa persentase didasari oleh sesi-sesi yang ada di dalam kelas yaitu bermain bebas, salamsalam, kegiatan inti, kegiatan refleksi dan kegiatan penutup. Persentase kemunculan perilaku diperoleh melalui penghitungan sebagai berikut:

$$
\% \text { Kemunculan Perilaku }=\frac{\text { Jumlah perilaku disregulasi }}{\text { Nilai maksimal kemunculan perilaku }} \times 100 \%
$$


Asesmen terkait perilaku disregulasi emosi dilakukan selama enam kali. Pelaksanaan waktu observasi menyesuaikan dengan jadwal sekolah anak. Perilaku yang diamati adalah perilaku yang muncul pada kelas bukan pada masing-masing anak. Berdasarkan enam kali pengambilan data, kemunculan respon disregulasi emosi yang ditampilkan oleh subyek dapat dilihat pada diagram berikut ini:

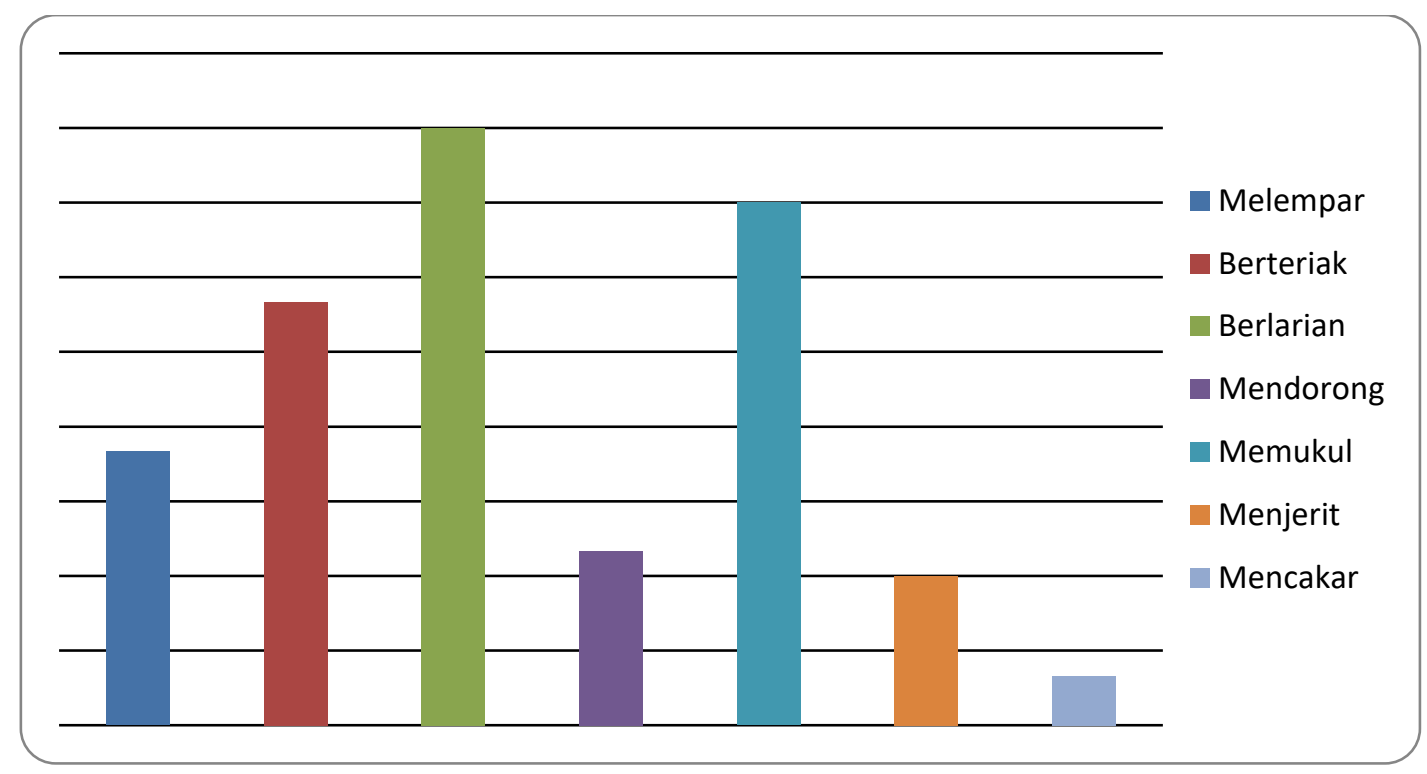

Gambar 1. Persentase Kemunculan Perilaku Disregulasi Emosi Periode Baseline

Diagram di atas menunjukkan perilaku disregulasi emosi muncul secara konsisten selama enam kali pertemuan Perilaku yang nilai persentasenya lebih besar adalah berlarian $(80 \%)$ dan memukul teman $(70 \%)$, sedangkan perilaku yang jarang muncul adalah mencakar $(6,6 \%)$.

\section{DISKUSI}

Penelitian mengenai regulasi emosi dan budaya telah dilakukan oleh Eisenberg, Liew dan Pidada (2001). Penelitian tersebut menunjukkan bahwa ekspresi emosi negatif yang ditampilkan oleh orang tua Indonesia (sebagian besar adalah ibu) dikaitkan dengan hasil negatif pada regulasi emosi anak meskipun tidak ada permusuhan atau kata-kata kasar yang ditunjukkan. Ibu sebagai sosok yang terdekat dengan anak dianggap memiliki attachment yang erat dengan anak. Attachment antara ibu dan anak disinyalir menjadi kunci dari perkembangan regulasi emosi anak (Callear, 2016). Anak yang memiliki secure attachment dengan orang tuanya akan cepat menunjukkan fleksibilitas saat menghadapi situasi yang membuatnya stress dan cenderung kooperatif dan relatif bebas dari kemarahan (Bretherton, 1992). Anak yang memiliki secure attachment cenderung lebih mampu mengenali dan memahami emosi mereka dan memiliki pengalaman tidak 
menyenangkan yang lebih rendah dibandingkan dengan anak-anak yang memiliki insecure attachment (Fonagy, Steele, Morgan, Steele \& Higit dalam Han, 2009; Mikulincer \& Florian dalam Han, 2009). Temuan penelitian tersebut sesuai dengan teori ekologi dimana perubahan yang terjadi pada lingkungan dan implikasinya mempengaruhi kehidupan dan perkembangan manusia di dalamnya (Bronfenbrenner, 1975). Bronfenbrener (1979) mengatakan bahwa attachment harus di perdalam pada microsystem dari hubungan di dalam keluarga.

Secara langsung maupun tidak orang tua memiliki pengaruh pada perkembangan disregulasi emosi anak. Pendekatan langsung yang dilakukan oleh orang tua adalah dengan mengajarkan anak bagaimana cara meregulasi emosi sedangkan pendekatan tidak langsung terjadi ketika orang tua berusaha mengatur tuntuan emosi yang terjadi pada kehidupan keluarga (Meyer \& Thompson, 2007). Disregulasi emosi yang muncul pada diri anak merupakan hasil dari peniruan apa yang dilihat oleh anak. Cara orang tua atau orang dewasa lainnya dalam meregulasi emosi ataupun berinteraksi dan kemudian ditiru oleh anak merupakan model (Bandura dalam Feist \& Feist, 2013).

Pada penelitian ini, belum ditemukan lebih lanjut apakah penyebab dari munculnya perilaku disregulasi emosi pada anak-anak usia prasekolah berdasarkan pola asuh yang diterapkan khususnya oleh ibu atau faktor lainnya. Salah satu faktor yang dianggap mempengaruhi munculnya disregulasi emosi pada anak adalah kondisi lingkungan. Kebudayaan serta lingkungan sekitar merupakan sistem ekologi yang berada pada kehidupan anak. Albert \& Mesquita (2007) menyatakan bahwa proses sosial, psikologis dan regulasi emosi bermakna secara bervariasi di berbagai budaya. Pada beberapa kebudayaan di Asia lebih menekanan pada kehidupan sosial yang harmonis dan tidak menunjukkan ekspresi marah tapi sangat mementingkan rasa malu (Papalia \& Martorell, 2012). Orang tua cenderung akan lebih memberi peringatan kepada anak untuk tidak menampilkan emosi marah karena malu akan penilaian masyarakat sekitar. Sebuah penelitian mengungkapkan bahwa selama masa kanak-kanak, orang tua dari Asia Timur mengajarkan anaknya untuk menunjukkan emotional reserve daripada emotional expressivity (Calkin, 2012; Kagan, 2013; dalam Santrock 2011). Anak-anak akan langsung dialihkan perhatiannya dibadingkan diberikan kesempatan untuk mengenali dan menggali cara menghadapi perasaan tersebut. Penelitian lain yang dilakukan di India menunjukkan bahwa keluarga dan hubungan interpersonal sangatlah penting, anak-anak lebih diajarkan untuk mengingat kebaikan yang pernah dilakukan orang lain dibandingkan mengajarkan konsep-konsep mengenai emosi marah (Martini \& Raval 2011; Raval et al.,2014 dalam Suchday, 2015). Pada umumnya, di Indonesia orang-orang yang tidak mengekspresikan emosinya cenderung lebih dihargai khususnya jika hal tersebut mengganggu fungsi kelompok dan hubungan interpersonal (Mulder, 1996; Wellenkamp, 1995). Secara khusus, pada suku Jawa di Indonesia, anak-anak diajarkan untuk lebih membina hubungan sosial yang harmonis dan menutupi emosi mereka (Williams, 1991 dalam Eisenberg, Liew \& Pidada, 2001).

Selain kondisi lingkungan dan budaya, status sosial ekonomi menengah ke bawah dianggap berperan pada permasalahan disregulasi emoi anak. Kemiskinan dianggap menjadi salah satu faktor yang mempengaruhi regulasi emosi pada diri anak (Izard et al, 2008). Kemiskinan dianggap berasosiasi dengan adanya tekanan dalam keluarga, orang 
tua dengan psikopatologi, kekerasan dalam lingkungan tetangga serta ketidakstabilan keluarga yang tercermin dalam perilaku disregulasi emosi anak pada lingkup ruang kelas (McLyod, 1998). Hal ini tidak sesuai dengan temuan penelitian ini dimana sampel merupakan anak-anak yang berada pada status sosial ekonomi menengah ke atas. Sejalan dengan itu Callear (2016) berpendapat bahwa variabilitas yang berperan penting di dalam menghasilkan disregulasi emosi adalah tempramen. Namun pada anak, tempramen bukanlah sesuatu yang mudah dilihat dan terukur.

\section{SIMPULAN DAN DIKSUSI}

Hasil penelitian menunjukkan bahwa pada anak usia prasekolah perilaku disregulasi emosi merupakan ketidakmampuan seseorang dalam mengekspresikan, mengetahui dan mengatur emosi secara tept. Perilaku disregulasi emosi yang muncul dapat berupa berteriak, melempar benda, berlarian, menjambak ataupun menangis. Jika dibiarkan terus menerus perilaku ini akan berpotensi menjadi risiko dalma pembentukan perilaku agresif. Ada banyak faktor yang mempengaruhi disregulasi emosi. Status sosial ekonomi dikatakan menjadi hal yang ikut mempengaruhi. Pada penelitian ini tidak ditemukan adanya pengaruh status sosial ekonomi terhadap kemunculan perilaku disregulasi emosi.

Peneliti belum menemukan secara pasti apa faktor utam adari pembentukan perilaku disregulasi emosi pada anak. Pada penelitian berikutnya disarankan untuk lebih rinci lagi memperhatikan faktor-faktor yang berpotensi mempengaruhi perilaku disregulasi emosi. Selain itu, diperlukan adanya program intervensi terkait kemunculan dari perilaku disregulasi emosi.

\section{REFERENSI}

Achenbach, T. M., Edelbrock, C., Howell, C.T. (1987). Empirically based assessment of the behavioral/emotional problems of 2- and 3- year-old children. Journal of Abnormal Child Psychology, 15 (4), 629-650.

Albert, D., Mesquita, B. (2007). The cultural regulation of emotions. New York City: Guilford Press.

Armga, C.J., Blunk, M.E., Russell, M.E., (2017). The role of teachers in peer conflict: implications for teacher reflections. Teacher Development. DOI: 10.1080/13664530.2016.1273847.

Basilio, M., Whitebread, D., (2012). The emergence and early development of selfregulation in young children. 16 (1).

Bretherton, I., (1992). The origins of attachment theory: John Bowlby and Mary Ainsworth. Developmental Psychology, 28(5), 759-775.

Bronfenbrenner, U. (1975). Reality and research in the ecology of human development. Proceedings of the American Philosophical Society, 119(6), 439-469. 
Bronfenbrenner, U. (1979). The Ecology of Human Development: Experiments by Nature and Design. Cambridge, MA: Harvard University Press.

Callear, A et al. (2016). Understanding the structure of children's emotion-regulation strategies. International Journal of Behavioral Development, 1-7. DOI: $10.1177 / 0165025416647525$.

Crain, W. (2011). Theories of development concept and applications 5ed. New York: Routledge.

Denham, S. A., Caverly, S., Schmidt, M., Blair, K., DeMulder, E., Caal, S., Hamada, H., Mason, T. (2002). Preschool understanding of emotions: contributions to classroom anger and aggression. The Journal of Child Psychology and Psychiatiary. DOI: 10.1111/1469-7610.00139.

Denham, S., Blair, K.A., DeMulder., E., Levtas, J., Sawyer, A., Auerbach-Major, S., \& Queenan, P. (2003). Preschool Emotional Competence: Pathway to Social Competence? Child Development, 74 (1), 238-256.

Denham, S., Bassett, H. H., \& Wyatt, T. (2007). The socialization of emotional competence. In J. Grusec \& P. Hastings (Eds.), Handbook of socialization (pp. 614-637). New York, NY: Guilford Press.

Dennis, T. A., Cole, P. M., Wiggins, C. N., \& Cohen, L. H. (2009). The functional organization of preschool-age children's emotion expressions and actions in challenging situations. Emotion, 9, 520-530.

Dickstein, S., Gouley, K., Miller, A., Seifer, R., \& Shields, A. (2004). Emotions and Behaviors in the Head Start Classroom: Associations Among Observed Dysregulation, Social Competence, and Preschool Adjustment. Early Education and Development. DOI: 10.1207/s15566935eed1502_2.

Eisenberg, N., Pidada, S., \& Liew, J. (2001). The Relations of Regulation and Negative Emotionality to Indonesian Children's Social Functioning. Child Development, 72 (6), 1747-1763.

Gestwicki, C. (2007). Developmentaly Appropriate Practice: Curriculum And Development In Early Education $3^{\text {rd }}$ ed. Canda: Thomson Delmar Learning.

Havighurst S. S., Wilson, K. R., Harley, A. E., Koheo, C., Efron, D., Prior, M. R., (2013). Tuning into Kids: Reducing Young Children's Behavior Problems Using an Emotion Coaching Parenting Program. Child Psychiatry \& Human Development. 44 (2), 247-264

Izard, C. , King, A. K. et al (2008). Accelerating the development of emotion competence in Head Start children: Effects on adaptive and maladaptive behavior. Development and Psychopathology, 20, 369-397. DOI: 10.1017/S0954579408000175. 
Martini, T.S., \& Raval, V.V. (2011). Making the child understand: Socialization of emotion in urban India. Journal of Family Psychology, 25(6), 847-856.

Meyer, S. \& Thompson, R.A. (2007). Handbook of Emotion Regulation, First Edition: Socialization of Emotion Regulation in The Family. New York: The Guildford press.

Morrison, G.S. (2009). Early Childhood Education Today. New Jersey: Pearson International Edition.

Papalia, D., R. \& Feldman, G. M. (2014). Experience Human Development 13th ed. New Jersey. McGraw-Hill.

Raikes, H.A. (2006). Family emotional climate, attachment security and young children's emotion knowledge in a highrisk sample. Developmental Psychology. DOI: $10.1348 / 026151005 \times 70427$

Roll, J., Koglin, U., \& Petermann, F. (2012). Emotion Regulation and Childhood Aggression: Longitudinal Associations. Child Psychiatry Hum Dev. DOI 10.1007/s10578-012-0303-4.

Santrock, J. W. (2011). Life Span Development 13th ed. New York. McGraw-Hill.

Suchday, S. (2015). Anger and globalization among young people in India. In E. L. Grigorenko(Ed.), The global context for new directions for child and adolescent development. New Directions for Child and Adolescent Development, 147, 7784.

Wellenkamp, J. (1995). Cultural similarities and differences regarding emotional disclosure: Some examples from Indonesia and the Pacific. Washington, DC, US: American Psychological Association. 